\title{
Spondylometaphyseal dysplasia, A4 type
}

INSERM

\section{Source}

INSERM. (1999). Orphanet: an online rare disease and orphan drug data base.

Spondylometaphyseal dysplasia, A4 type. ORPHA:168555

Spondylometaphyseal dysplasia, A4 type is a rare primary bone dysplasia disorder

characterized by disproportionate short stature, severe femoral neck deformity, marked

metaphyseal abnormalities and platyspondyly consisting of ovoid vertebral bodies that have an anterior tongue-like deformity. 